\title{
Investigation of Chemical Composition, Antioxidant, Anticholinesterase and Anti-urease activities of Euphorbia helioscopia
}

\author{
Ebru Deveci ${ }^{1}$, Gülsen Tel-Çayan ${ }^{(1)}{ }^{*}$, , Mehmet Emin Duru ${ }^{1}$
}

1 Department of Chemistry, Faculty of Sciences, Muğla Sıtkı Koçman University, 48000, Muğla, Turkey

2 Department of Chemistry and Chemical Processing Technologies, Muğla Vocational School, Muğla Sitk1 Koçman University, 48000, Muğla, Turkey

\begin{abstract}
In this study, chemical composition, antioxidant, anticholinesterase and anti-urease activities of the essential oil, hexane, acetone, methanol and water extracts of Euphorbia helioscopia were investigated. The chemical composition of the essential oil was analyzed by GC and GC/MS and $\beta$-cubebene (19.3\%), palmitic acid $(12.2 \%)$ and caryophyllene oxide $(11.7 \%)$ were identified as major compounds. The antioxidant activity of essential oil and extracts was performed by several methods such as $\beta$-carotene-linoleic acid, DPPH', ABTS $^{\cdot+}$ radical scavenging, CUPRAC and metal chelating assays. The water extract showed higher antioxidant activity than BHA and $\alpha$-tocopherol in $\beta$-carotene-linoleic acid, DPPH', $\mathrm{ABTS}^{\cdot+}$ and CUPRAC assays with $\mathrm{IC}_{50}: 1.08 \pm 0.39,15.57 \pm 0.48,1.89 \pm 0.33$ and $12.50 \pm 0.11 \mu \mathrm{g} / \mathrm{mL}$ values, respectively. Also, the anticholinesterase and antiurease activities were tested against acetylcholinesterase (AChE), butyrylcholinesterase $(\mathrm{BChE})$ and urease enzymes, spectrophotometrically. The acetone extract $(81.23 \pm 0.58 \%)$ showed very close BChE inhibitory activity to galantamine. The hexane extract $(96.97 \pm 0.36 \%)$ of E. helioscopia showed higher anti-urease activity than thiourea $(96.93 \pm 0.17 \%)$ whereas the essential oil $(91.37 \pm 0.26 \%)$ indicated very close anti-urease activity to the standard.
\end{abstract}

\section{ARTICLE HISTORY}

Received: 13 June 2018

Accepted: 15 September 2018

\section{KEYWORDS}

Euphorbia helioscopia, Essential oil, Antioxidant activity, Anticholinesterase activity, Anti-urease activity

\section{INTRODUCTION}

Euphorbiaceae family is distributed in all parts of the world except the Antarctic continent with over 5000 taxa. Euphorbia species, the most well-known of this family, is represented by approximately 2150 taxa in the world, while there are 109 taxa in our country. Euphorbia species is known as 'Sütleğen' in Turkey and these species is characterized by milk latex tissues. In the folk medicine, Euphorbia species are used in the treatment of various diseases such as a migraine, gonorrhea, skin diseases, intestinal parasites and warts cures [1]. Until this time, it is seen that secondary metabolites such as terpenes, flavonoids, tannins, steroids, alkaloids, and lipids are isolated from Euphorbia species [2-5]. It has also been reported that

CONTACT: Gülsen TEL-ÇAYAN $\$ gulsentel@mu.edu.tr $\equiv$ Department of Chemistry and Chemical Processing Technologies, Muğla Vocational School, Muğla Sıtkı Koçman University, 48000, Muğla, Turkey Phone: +902522111514 FAX: +902522111471 
Euphorbia species have bioactive properties such as anti-inflammatory, antiarthritic, antiviral, antitussives, antitumor, anti-allergy, anti-asthma and antioxidant [1, 6-7].

Alzheimer's disease (AD) is a neurodegenerative disorder with clinical features such as memory loss, speech impairment and visuospatial defect [8]. Lack of acetylcholine, tau protein hyperphosphorylation, $\beta$-amyloid (A $\beta$ ) aggregation, oxidative stress, and neuroinflammation are promising approaches used in the treatment of Alzheimer's disease [9]. Reactive oxygen species (ROS), the major source of oxidative stress, cause oxidation of proteins and lipids in the brain causing Alzheimer's disease (AD) [10]. The most important approach to the treatment of $\mathrm{AD}$ is the inhibition of the acetylcholinesterase enzyme which leads to the breakdown of acetylcholine. Today, many drugs derived from synthetic and natural sources are used in the treatment of AD. Natural drugs are more preferred because of the harmful and toxic effects of synthetic drugs [11]. For this reason, researchers are increasingly interested in researching new sources of natural medicines. Herbal medicines have given promising results among the natural sources due to the existence of volatile oils and secondary metabolites.

When the literature studies are examined, it is seen that researchers related to the essential oil composition and the extracts obtained from plants and their biological activities have gained more importance in recent years. According to our knowledge, there have been a limited number of reports about phytochemical contents and bioactivities of E. helioscopia in the literature. Therefore, in this study, we aimed to evaluate chemical composition, antioxidant, anticholinesterase and anti-urease activities of the essential oil and the hexane, acetone, methanol and water extracts of E. helioscopia with the total phenolic and flavonoid contents in details.

\section{METHOD}

\subsection{Plant Material}

The aerial parts of E. helioscopia were collected from Yusufeli, Artvin, Turkey in August, 2016. The voucher specimen has been deposited at the herbarium of Natural Products Laboratory of Muğla Sitkı Koçman University.

\subsection{Instruments and Chemicals}

Bioactivity measurements were carried out on a 96-well microplate reader, SpectraMax $340 \mathrm{PC}^{384}$ (Molecular Devices, Silicon Valley, CA). The measurements and calculations of the activity results were evaluated by using Softmax PRO v5.2 software (Molecular Devices, Silicon Valley, CA). Chemical composition of the essential oils was performed using GC (Shimadzu GC-17 AAF, V3, 230V series gas chromatography, Japan) and GC/MS (Varian Saturn 2100T, USA).

Pyrocatechol, quercetin, $n$-hexane, methanol, ethanol, ferrous chloride, copper (II) chloride and ethylenediaminetetraacetic acid (EDTA) were purchased from E. Merck (Darmstadt, Germany). Butylatedhydroxyl anisole (BHA), $\alpha$-tocopherol, $\beta$-carotene, polyoxyethylene sorbitan monopalmitate (Tween-40), linoleic acid, Folin-Ciocalteu's reagent (FCR), neocuproine, 1,1-diphenyl-2-picryl-hydrazyl (DPPH), 2,2'-azino bis (3ethylbenzothiazoline-6-sulfonic acid) diammonium salt (ABTS), 3-(2-pyridyl)-5,6-di(2-furyl)1,2,4-triazine-5',5'-disulfonic acid disodium salt (Ferene), acetylcholinesterase (AChE) from electric eel (Type-VI-S, EC 3.1.1.7, 425.84 U/mg, Sigma, St. Louis, MO), butyrylcholinesterase (BChE) from horse serum (EC 3.1.1.8, 11.4 U/mg, Sigma, St. Louis, MO), ), urease [Type-III from Jack Beans, EC 232-656-0, 20990 U/g solid], 5,5'-dithiobis(2nitrobenzoic) acid (DTNB), galantamine, thiourea, acetylthiocholine iodide, and butyrylthiocholine chloride were purchased from Sigma Chemical Co. (Sigma-Aldrich GmbH, Sternheim, Germany). All other chemicals and solvents were of analytical grade. 


\subsection{Isolation of the Essential Oil}

The essential oil of dried aerial parts of E. helioscopia was extracted by hydrodistillation in a Clevenger type apparatus for $4 \mathrm{~h}$. The oil was dried over anhydrous sodium sulphate and stored under $+4^{\circ} \mathrm{C}$ until analyzed.

\subsection{Analysis of the Essential Oil}

\subsubsection{Gas chromatography (GC)}

A Flame Ionization Detector (FID) and a DB-5 fused silica capillary non-polar column ( $30 \mathrm{~m} \times 0.25 \mathrm{id}$., film thickness $0.25 \mu \mathrm{m}$ ) were used for GC analyses. The injector temperature and detector temperature were adjusted 250 and $270^{\circ} \mathrm{C}$, respectively. Carrier gas was $\mathrm{He}$ at a flow rate of $1.4 \mathrm{~mL} / \mathrm{min}$. Sample size was $1.0 \mu \mathrm{L}$ with a split ratio of $20: 1$. The initial oven temperature was held at $60^{\circ} \mathrm{C}$ for $5 \mathrm{~min}$, then increased up to $240^{\circ} \mathrm{C}$ with $4{ }^{\circ} \mathrm{C} / \mathrm{min}$ increments and held at this temperature for $10 \mathrm{~min}$. The percentage composition of the essential oil was determined with GC solution computer program.

\subsubsection{Gas chromatography-mass spectrometry (GC-MS)}

An Ion trap MS spectrometer and a DB-5 MS fused silica non-polar capillary column (30 $\mathrm{m} \times 0.25 \mathrm{~mm}$ ID, film thickness $0.25 \mu \mathrm{m}$ ) were used for the GC-MS analyses. Carrier gas was helium at a flow rate of $1.4 \mathrm{~mL} / \mathrm{min}$. The oven temperature was held at $60^{\circ} \mathrm{C}$ for $5 \mathrm{~min}$, then increased up to $240^{\circ} \mathrm{C}$ with $4^{\circ} \mathrm{C} / \mathrm{min}$ increments and held at this temperature for $10 \mathrm{~min}$. Injector and MS transfer line temperatures were set at $220^{\circ} \mathrm{C}$ and $290^{\circ} \mathrm{C}$, respectively. Ion source temperature was $200^{\circ} \mathrm{C}$. The injection volume was $0.2 \mu \mathrm{L}$ with a split ratio of 1:20. EI-MS measurements were taken at $70 \mathrm{eV}$ ionization energy. Mass range was from m/z 28 to $650 \mathrm{amu}$. Scan time $0.5 \mathrm{~s}$ with 0.1 inter scan delays. Identification of components of the essential oils was based on GC retention indices and computer matching with the Wiley, NIST-2005 and TRLIB Library as well as by comparison of the fragmentation patterns of the mass spectra with those reported in the literature and whenever possible, by co-injection with authentic compounds [12].

\subsection{Extraction}

The aerial parts of E. helioscopia were extracted separately with different solvents according to their increasing polarity: hexane, acetone, methanol at room temperature for $24 \mathrm{~h}$ and four times. Solvents were evaporated on a rotary evaporator to obtain hexane, acetone and methanol extracts. The remaining plant part was allowed to stand for one day with water at 80 ${ }^{\circ} \mathrm{C}$. The water extract was obtained by lyophilisation using a freeze-drier. All extracts were stored at $+4^{\circ} \mathrm{C}$ until analysis.

\subsection{Antioxidant Activity}

The total antioxidant activity of the essential oil and extracts was evaluated using $\beta$ carotene-linoleic acid test system as previously reported in the literature [13]. Radical scavenging activities were measured by DPPH free and ABTS cation radical scavenging assays [13]. Reducing powers were determined using CUPRAC assays [13]. Metal chelating activity on ferrous ions was determined using the method described in the literature [14].

\subsection{Total Phenolic and Flavonoid Content}

The phenolic content of extracts was stated as microgram of pyrocatechol equivalents (PEs) [15]. The phenolic contents were calculated according to the following equation that was obtained from standard pyrocatechol graph:

$$
\text { Absorbance }=0.0078[\text { pyrocatechol }(\mu \mathrm{g})]+0.0623\left(r^{2}, 0.9992\right)
$$


Measurement of flavonoid content of the extracts was based on the aluminum nitrate method and results were expressed as microgram of quercetin equivalents [16]. The flavonoid contents were calculated according to following equation that was obtained from the standard quercetin graph:

Absorbance $=0.0412[$ quercetin $(\mu \mathrm{g})]-0.0662\left(r^{2}, 0.9998\right)$

\subsection{Enzyme Inhibitory Activity}

Anticholinesterase and anti-urease activities were measured using Ellman et al. [17] and Weatherburn [18] respectively.

\subsection{Statistical Analysis}

All data on antioxidant, anticholinesterase and anti-urease tests were the average of three parallel sample measurements. Data were recorded as mean \pm S.E.M. Significant differences between means were determined by student's test, $p$ values $<0.05$ were regarded as significant.

\section{RESULTS AND DISCUSSION}

\subsection{Essential Oil Composition}

GC-FID and GC/MS techniques were used to determine the chemical composition of the essential oil of E. helioscopia. The chemical composition of the essential oil, retention indices and relative percentage (\%) of compounds are shown in Table 1 . Thirty compounds, representing about $99.9 \%$ of the essential oil of E. helioscopia were identified. $\beta$-cubebene $(19.3 \%)$, palmitic acid (12.2\%) and caryophyllene oxide $(11.7 \%)$ were identified as major compounds, respectively. Sesquiterpene hydrocarbons $(34.8 \%)$ were the most abundant compounds in the essential oil.

There is only one study about the essential oil composition of E. helioscopia. In that report, the chemical composition of the essential oil of E. helioscopia collected from Greece, was studied by Fokialakis et al. [19] and phytol (21.2\%), $\beta$-caryophyllene $(10.0 \%)$ and docosanoic acid methyl ester $(8.1 \%)$ were found as major compounds. Season, the geographical location and date of collection cause these differences in the chemical composition of the essential oil [20].

Table 1. Chemical composition of the essential oil of E. helioscopia

\begin{tabular}{cclcc}
\hline No & RI $^{\mathbf{a}}$ & Compounds & $\begin{array}{c}\text { Percentage } \\
\boldsymbol{\%}^{\mathbf{b}}\end{array}$ & $\begin{array}{c}\text { Identification } \\
\text { methods }^{\mathbf{c}}\end{array}$ \\
\hline 1 & 1144 & Cis- $\beta$-terpineol & 0.4 & Co-GC, MS, RI \\
2 & 1159 & Terpinene-4-ol & 0.3 & Co-GC, MS, RI \\
3 & 1178 & $\alpha$-Terpineol & 0.6 & Co-GC, MS, RI \\
4 & 1189 & Borneol & 0.9 & Co-GC, MS, RI \\
5 & 1290 & Thymol & 0.2 & Co-GC, MS, RI \\
6 & 1299 & Carvacrol & 0.2 & Co-GC, MS, RI \\
7 & 1359 & $\beta$-Damascenone & 0.6 & MS, RI \\
8 & 1381 & $\beta$-Bourbonene & 0.5 & Co-GC, MS, RI \\
9 & 1394 & $\beta$-Cubebene & 19.3 & MS, RI \\
10 & 1424 & $\beta$-Caryophyllene & 1.6 & Co-GC, MS, RI \\
11 & 1442 & $\tau$-Elemene & 9.3 & MS, RI \\
12 & 1458 & $\alpha$-Farnesene & 1.7 & MS, RI \\
13 & 1478 & $\tau$-Muurolene & 1.6 & MS, RI \\
14 & 1512 & $\delta$-Cadinene & 0.8 & MS, RI \\
\hline
\end{tabular}


Table 1. Continues

\begin{tabular}{|c|c|c|c|c|}
\hline No & $\mathbf{R I}^{\mathbf{a}}$ & Compounds & $\begin{array}{c}\text { Percentage } \\
\%^{\mathrm{b}}\end{array}$ & $\begin{array}{c}\text { Identification } \\
\text { methods }^{\mathrm{c}}\end{array}$ \\
\hline 15 & 1538 & $\alpha$-Cadinol & 2.5 & MS, RI \\
\hline 16 & 1576 & Spathulenol & 9.3 & Co-GC, MS, RI \\
\hline 17 & 1580 & Caryophyllene oxide & 11.7 & Co-GC, MS, RI \\
\hline 18 & 1720 & Myristic acid & 1.9 & Co-GC, MS, RI \\
\hline 19 & 1833 & Hexahydrofarnesly acetone & 5.3 & MS, RI \\
\hline 20 & 1851 & Pentadecanoic acid & 0.4 & Co-GC, MS, RI \\
\hline 21 & 1942 & Phytol & 6.9 & MS, RI \\
\hline 22 & 2001 & Palmitic acid & 12.2 & Co-GC, MS, RI \\
\hline 23 & 2100 & Heneicosane & 1.9 & MS, RI \\
\hline 24 & 2108 & Linolenic acid & 3.6 & MS, RI \\
\hline 25 & 2120 & Linoleic acid & 1.6 & Co-GC, MS, RI \\
\hline 26 & 2140 & Octadecane, 3-ethyl-5-(2-ethyl butyl) & 0.3 & MS, RI \\
\hline 27 & 2200 & Docasane & 0.2 & MS, RI \\
\hline 28 & 2225 & Phytol acetate & 2.2 & MS, RI \\
\hline 29 & 2300 & Tricosane & 0.7 & MS, RI \\
\hline \multirow[t]{8}{*}{30} & 2400 & Tetracosane & 1.2 & MS, RI \\
\hline & & Oxygenated monoterpenes & 2.6 & \\
\hline & & Sesquiterpene hydrocarbons & 34.8 & \\
\hline & & Oxygenated sesquiterpenes & 23.5 & \\
\hline & & Oxygenated diterpenes & 9.1 & \\
\hline & & Others & 29.9 & \\
\hline & & Total identified (\%) & 99.9 & \\
\hline & & Total number of compounds & 30 & \\
\hline
\end{tabular}

a Retention indices on DB-5 fused silica column. ${ }^{\mathrm{b}}$ Percentage concentration. ${ }^{\mathrm{c}}$ Identification methods: Co-I: Co-injection: based on comparison with authentic compounds; MS: based on comparison with WILEY, ADAMS and NIST 08 MS databases; RI: based on comparison of calculated with those reported in ADAMS and NIST 08.

\subsection{Total Phenolic and Total Flavonoid Contents}

Phenolic and flavonoid compounds are responsible for the bioactive properties of the natural compounds. Phenolic compounds are of great interest to researchers because of their beneficial effects on oxidative stress-related diseases in addition to their antioxidant. Flavonoids scavenge many oxidation molecules such as singlet oxygen and other free radicals. Also, flavonoids prevent the formation of reactive oxygen species [21,22].

The calibration curve of pyrocatechol $(0.0078$ [pyrocatechol $\left.(\mu \mathrm{g})]+0.0623 ; r^{2}, 0.9992\right)$ was used to determine the total phenolic content and quercetin $(0.0412$ [quercetin $(\mu \mathrm{g})$ ] $\left.0.0662 ; r^{2}, 0.9998\right)$ for the total flavonoid content. Table 2 presents the total phenolic and flavonoid contents of the different extracts of E. helioscopia. Among the extracts, water extract has the highest phenolic (161.20 $\pm 0.98 \mu \mathrm{g}$ PEs/mg) and flavonoid $(11.22 \pm 0.05 \mu \mathrm{g}$ QEs/mg) contents, followed by the methanol extract and the acetone extract. It is well known that phenolic compounds are secondary metabolites responsible for antioxidant activity. The water extract containing the highest amount of total phenolic and flavonoid compounds showed the highest antioxidant activity in all studied tests.

Maoulainine et al. [23] studied the total phenolic and flavonoid contents of the methanol and ethanol extracts of E. helioscopia and the highest phenolic and flavonoid contents were found in the methanol extracts $(51.49 \pm 0.012 \mathrm{mg}$ GAE$/ \mathrm{g}$ dry weight and $11.38 \pm 0.004 \mathrm{mg}$ 
QE/dry weight, respectively). Total flavonoid contents of E. helioscopia collected from four different regions of Chongqing were investigated by Dan et al. [24] and contents of total flavonoids were found in the range of 5.485-5.742 mg/g and the results obtained are consistent with the literature. Total phenolic and flavonoid contents of the hexane, acetone and water extracts of E. helioscopia were determined for the first time in our study.

Table 2. Total phenolic and total flavonoid contents of the extracts of E. helioscopia

\begin{tabular}{llcc}
\hline & $\begin{array}{c}\text { Total phenolic contents } \\
\boldsymbol{\mu g} \text { PEs/mg extracts }\end{array}$ & $\begin{array}{c}\text { Total flavonoid contents } \\
\boldsymbol{\mu g}^{\mathbf{b}} \mathbf{\text { QEs}} / \text { mg extract }^{\mathbf{c}}\end{array}$ \\
\hline & Hexane & $10.40 \pm 0.26$ & $1.01 \pm 0.01$ \\
E. helioscopia & Acetone & $44.98 \pm 0.58$ & $3.93 \pm 0.17$ \\
& Methanol & $55.17 \pm 0.83$ & $5.36 \pm 0.52$ \\
& Water & $161.20 \pm 0.98$ & $11.22 \pm 0.05$ \\
\hline
\end{tabular}

${ }^{a}$ Values expressed are means \pm S.E.M. of three parallel measurements. $(p<0.05)$

b PEs, pyrocatechol equivalents.

${ }^{\mathrm{c}} \mathrm{QEs}$, quercetin equivalents.

\subsection{Antioxidant Activity}

The essential oil and the hexane, acetone, methanol and water extracts of E. helioscopia were screened for their antioxidant activity by using five methods, namely $\beta$-carotene-linoleic acid, DPPH free radical scavenging, ABTS cation radical scavenging, cupric-reducing antioxidant capacity (CUPRAC) and metal chelating activity. All of the extracts and the essential oil showed antioxidant activities in a dose-dependent manner. Table 3 shows the $\mathrm{IC}_{50}$ values of the extracts and standard compounds (BHA, $\alpha$-tocopherol, and EDTA).

Table 3. Antioxidant activity of the essential oil and extracts of E. helioscopia by $\beta$-Carotene-linoleic acid, DPPH ${ }^{*}$ ABTS $^{*+}$, CUPRAC and metal chelating assays ${ }^{\mathrm{a}}$

\begin{tabular}{|c|c|c|c|c|c|c|}
\hline & & \multicolumn{5}{|c|}{ Antioxidant Activity } \\
\hline & & $\begin{array}{l}\text { B-Carotene- } \\
\text { linoleic acid } \\
\text { assay } \\
\text { IC } \mathrm{C}_{50} \\
(\mu \mathrm{g} / \mathrm{mL})\end{array}$ & $\begin{array}{c}\text { IC } 50 \\
(\mu \mathrm{g} / \mathrm{mL})\end{array}$ & $\begin{array}{c}\text { ABTS }^{\cdot+} \\
\text { assay } \\
\text { IC }_{50} \\
(\mu \mathrm{g} / \mathrm{mL})\end{array}$ & $\begin{array}{c}\text { CUPRAC } \\
\text { assay }\end{array}$ & $\begin{array}{l}\text { Metal chelating } \\
\text { assay } \\
\text { Inhibition } \\
(\%)^{\mathrm{c}}\end{array}$ \\
\hline \multirow{5}{*}{$\begin{array}{l}\text { E. } \\
\text { helioscopia }\end{array}$} & Essential oil & $113.79 \pm 0.55$ & $2.81 \pm 0.75^{\mathrm{c}}$ & $21.45 \pm 0.43^{\mathrm{c}}$ & $512.11 \pm 0.72$ & $-\mathrm{e}$ \\
\hline & $\begin{array}{l}\text { Hexane } \\
\text { extract }\end{array}$ & $579.81 \pm 0.71$ & $4.57 \pm 0.97^{\mathrm{c}}$ & $17.45 \pm 0.68^{\mathrm{c}}$ & $295.23 \pm 0.89$ & $29.40 \pm 0.27$ \\
\hline & $\begin{array}{l}\text { Acetone } \\
\text { extract }\end{array}$ & $2.33 \pm 0.16$ & $90.18 \pm 0.22$ & $17.15 \pm 0.19$ & $53.03 \pm 0.49$ & $19.85 \pm 0.31$ \\
\hline & $\begin{array}{l}\text { Methanol } \\
\text { extract }\end{array}$ & $1.14 \pm 0.21$ & $16.43 \pm 0.67$ & $15.10 \pm 0.82$ & $18.20 \pm 0.35$ & $13.51 \pm 0.12$ \\
\hline & $\begin{array}{l}\text { Water } \\
\text { extract }\end{array}$ & $1.08 \pm 0.39$ & $15.57 \pm 0.48$ & $1.89 \pm 0.33$ & $12.50 \pm 0.11$ & $79.31 \pm 0.51$ \\
\hline \multirow[b]{2}{*}{ Standards } & a-Tocophero & $2.10 \pm 0.08$ & $37.20 \pm 0.41$ & $38.51 \pm 0.54$ & $66.72 \pm 0.81$ & $N T^{\mathrm{d}}$ \\
\hline & $\begin{array}{l}\text { BHA } \\
\text { EDTA }\end{array}$ & $\begin{array}{c}1.34 \pm 0.04 \\
N T^{\mathrm{d}}\end{array}$ & $\begin{array}{c}19.80 \pm 0.36 \\
N T^{\mathrm{d}}\end{array}$ & $\begin{array}{c}11.82 \pm 0.09 \\
N T^{\mathrm{d}}\end{array}$ & $\begin{array}{c}24.40 \pm 0.69 \\
N T^{\mathrm{d}}\end{array}$ & $\begin{array}{c}N T^{\mathrm{d}} \\
94.7 \pm 0.6\end{array}$ \\
\hline \multicolumn{7}{|c|}{$\begin{array}{l}\text { a: } \text { IC }_{50} \text { values represent the means } \pm \text { SEM of three parallel measurements }(p<0.05) \text {. } \\
\text { b: } A_{0.50} \text { values represent the means } \pm \text { SEM of three parallel measurements }(p<0.05) \text {. } \\
\text { c: } \% \text { inhibition of } 200 \mu \mathrm{g} / \mathrm{mL} \text { concentration of the essential oil and extracts of Euphorbia helioscopia. } \\
\text { d: NT: not tested. } \\
\text { e:- Not active. }\end{array}$} \\
\hline
\end{tabular}

In all studied methods, the highest antioxidant activity was found in the water extract and followed by the methanol extract. The water extract was found to be more active than BHA and $\alpha$-tocopherol which used as standards in $\beta$-carotene-linoleic acid, DPPH${ }^{*}$, ABTS $^{\circ+}$ and 
CUPRAC assays with $\mathrm{IC}_{50}: 1.08 \pm 0.39,15.57 \pm 0.48,1.89 \pm 0.33$ and $12.50 \pm 0.11 \mu \mathrm{g} / \mathrm{mL}$ values, respectively. The methanol extract exhibited higher antioxidant activity than BHA and $\alpha$ tocopherol in $\beta$-carotene-linoleic acid, DPPH ${ }^{*}$ and CUPRAC assays with $\mathrm{IC}_{50}: 1.14 \pm 0.21$, $16.43 \pm 0.67$ and $18.20 \pm 0.35 \mu \mathrm{g} / \mathrm{mL}$, respectively. Also, in $\mathrm{ABTS}^{\circ+}$ assay, the methanol extract $\left(\mathrm{IC}_{50}: 15.10 \pm 0.82 \mu \mathrm{g} / \mathrm{mL}\right.$ ) showed higher antioxidant activity than $\alpha$-tocopherol $\left(\mathrm{IC}_{50}\right.$ : $38.51 \pm 0.54 \mu \mathrm{g} / \mathrm{mL})$.

In previous studies, antioxidant activity of the dichloromethane and methanol extracts of E. helioscopia were evaluated by thin layer chromatography (TLC) autographic assay method, using $\mathrm{DPPH}^{\circ}$ as spray reagent. At $100 \mu \mathrm{g}$ concentration, when methanol extract appeared as a yellow spot against purple background, dichloromethane extract did not respond to DPPH ${ }^{*}$ [1]. In a report of Rauf et al. [25], DPPH' scavenging effects of various extracts of E. helioscopia were determined and activity was decreased in order of methanol>ethyl acetate > ethanol>chloroform> hexane. In another study, antioxidant activity of aqueous, ethanol, petroleum ether, chloroform and methanol extracts of leaves, stem parts, and also latex of $E$. helioscopia were evaluated by using DPPH, TAC, FRAP, FTC and BCL assays. The highest antioxidant activity was found in latex and followed by the methanol extract of leaves in all the methods. The other extracts also showed significant antioxidant activity [26]. Antioxidant properties of the methanol and ethanol extracts of E. helioscopia leaves, flowers and stem were examined by using the $\mathrm{DPPH}^{*}$ scavenging assay by Maoulainine et al. [23]. The highest radical scavenging effect was observed in flowers methanol extract with $\mathrm{IC}_{50}$ value of $26.66 \pm 0.000$ $\mu \mathrm{g} / \mathrm{mL}$. The results obtained in our study are similar to these findings.

When literature findings are examined, it is seen that $\mathrm{DPPH}^{\bullet}$ scavenging assay was generally used for testing to antioxidant properties of E. helioscopia. In our study, antioxidant activities of the essential oil and the hexane, acetone, methanol and water extracts of $E$. helioscopia were evaluated by using $\beta$-carotene-linoleic acid, ABTS cation radical scavenging, cupric-reducing antioxidant capacity and metal chelating activity assays for the first time.

\subsection{Anticholinesterase Activity}

Acetylcholinesterase (AChE) and butyrylcholinesterase (BChE) inhibitory activities of the essential oil and the extracts of E. helioscopia compared with that of galantamine were given in Table 4 . The inhibitory activity of the extracts was divided into three separate classes; potent $(>50 \%)$, moderate $(30-50 \%)$, inactive or low $(<30 \%)$ activity [27]. According to this classification, when the hexane extract $(47.49 \pm 0.19 \%)$ of E. helioscopia showed moderate inhibitory activity against $\mathrm{AChE}$, all other extracts showed low inhibitory activity against AChE. All extracts except methanol and water extracts of E. helioscopia were found to be potent inhibitors against BChE. Moreover, the acetone extract $(81.23 \pm 0.58 \%)$ of E. helioscopia exhibited very close BChE inhibitory activity to galantamine $(82.23 \pm 0.67 \%)$.

In previous studies, anticholinesterase activities of different Euphorbia species were investigated. Pisano et al. [28] evaluated cholinesterase inhibitory activities of aqueous and alcoholic extracts from leaves, stems, and flowers of $E$. characias and ethanol leaves extract showed fifty times more activity than galantamine. Cholinesterase inhibitory activities of the methanolic extracts of $E$. denticulata (flowers, leaf, stem, and mix of aerial parts) were studied by Zengin et al. [29] and the extracts were reported as medium-low activator for AChE and BChE. In a different study of Euphorbia species, E. hebecarpa is tested for AChE inhibitory activity and was inactive [30]. Cholinesterase inhibitory activities of the essential oil and hexane, acetone, methanol and water extracts of E. helioscopia were studied for the first time in this report. 
Table 4. Anticholinesterase and anti-urease inhibitory activities of the essential oil and the extracts of E. helioscopia ${ }^{\mathrm{a}}$

\begin{tabular}{llccc}
\hline & & \multicolumn{2}{c}{ Anticholinesterase Activity } & Anti-urease Activity \\
\cline { 3 - 4 } & & AChE assay & BChE assay & \\
\hline \multirow{4}{*}{ E. helioscopia } & Essential oil & $18.68 \pm 0.16$ & $50.85 \pm 0.67$ & $91.37 \pm 0.26$ \\
& Hexane extract & $47.49 \pm 0.19$ & $54.32 \pm 0.92$ & $96.97 \pm 0.36$ \\
& Acetone extract & $8.74 \pm 0.14$ & $81.23 \pm 0.58$ & $54.17 \pm 0.92$ \\
& Methanol extract & $6.97 \pm 0.07$ & $20.88 \pm 0.15$ & $70.94 \pm 0.32$ \\
& Water extract & $0.67 \pm 0.02$ & $9.87 \pm 0.31$ & $19.32 \pm 0.18$ \\
\hline Standards & Galantamine & $80.41 \pm 0.98$ & $82.23 \pm 0.67$ & $N T^{\mathrm{b}}$ \\
& Thiourea & $N T^{\mathrm{b}}$ & $N T^{\mathrm{b}}$ & $96.93 \pm 0.17$ \\
\hline
\end{tabular}

${ }^{\mathrm{a}}$ : Inhibition \% of $200 \mu \mathrm{g} / \mathrm{mL}$ concentration of the essential oil and the extracts of E. helioscopia

b: NT: not tested.

\subsection{Anti-urease Activity}

Since urease inhibitors can be used as potential drugs in the treatment of ulcer diseases, the discovery of new inhibitors is gaining in importance. Table 4 shows anti-urease activity by inhibition (\%) at $200 \mu \mathrm{g} / \mathrm{mL}$ concentration. The hexane extract $(96.97 \pm 0.36 \%)$ of $E$. helioscopia showed higher anti-urease activity than thiourea $(96.93 \pm 0.17 \%)$ used as a standard. In addition, the essential oil $(91.37 \pm 0.26 \%)$ exhibited very close anti-urease activity to the standard.

Natural compounds isolated from Euphorbia species exhibiting anti-urease activity are reported in the literature. Ahmad et al. [31,32] and Lodhi et al. [33] isolated five diterpenes esters from E. decipiens inhibited urease enzyme and the first natural urease inhibitor was discovered by Ahmad et al. [31]. In a different study, the methanolic bark fraction of $E$. umbellata was reported to exhibit $78.6 \%$ inhibition at $1024 \mu \mathrm{g} / \mathrm{mL}$ concentration [34]. In our study, the essential oil and all the extracts except the water extract were highly active, and these results are similar to previous studies on other Euphorbia species.

\section{CONCLUSION}

In this report, antioxidant, anticholinesterase and anti-urease activities of the essential oil and various extracts of E. helioscopia were determined with the total phenolic and flavonoid contents. Also, chemical composition of the essential oil was analyzed by GC and GC/MS and totally 30 compounds were determined. The water extract with the highest amount of total phenolic and flavonoid contents exhibited the highest antioxidant activities in all assays. Furthermore, the acetone extract exhibited very close BChE inhibitory activity to galantamine. In anti-urease activity test, when the hexane extract showed higher activity than thiourea, the essential oil exhibited very close activity to the standard. Consequently, E. helioscopia could become a source of potential bioactive compounds in pharmaceutical and food industries with strong enzyme inhibitory and antioxidant activities. However, further studies are needed for discovering of new natural bioactive compounds from these species.

\section{Conflict of interest}

The authors declare that they have no conflict of interest.

\section{ORCID}

Gülsen TEL ÇAYAN (i) http://orcid.org/0000-0002-1916-7391

\section{REFERENCES}

[1] Uzair, M., Loothar, B.A., \& Choudhary, B.A. (2009). Biological screening of Euphorbia helioscopia L. Pakistan Journal of Pharmaceutical Sciences, 22(2), 184-186. 
[2] Nazir, M., Ahmad, W., \& Kreiser W. (1998). Isolation and NMR-assignments of 19aHlupeol from E. helioscopia Linn (N.O. Euphorbiaceae). Pakistan Journal of Scientific and Industrial Research, 41, 6-10.

[3] Zhang, W., \& Guo, Y.W. (2006). Chemical studies on the constituents of the Chinese medicinal herb Euphorbia helioscopia L. Chemical and Pharmaceutical Bulletin, 54(7), 1037-1039.

[4] Kosemura, S., Shizuri, Y., \& Yamamura, S. (1985). Isolation and structures of euphohelins, new toxic diterpenes from Euphorbia helioscopia. Bulletin of the Chemical Society of Japan, 58, 3112-3117.

[5] Lee, S.H., Tanaka, T., Nonaka, G., \& Nishioka, I. (1991). Tannins and related-compounds .105. monomeric and dimeric hydrolyzable tannins having a dehydrohexahydroxydiphenoyl group, supinanin, euphorscopin, euphorhelin and jolkianin, from Euphorbia species. Chemical and Pharmaceutical Bulletin, 39, 630-638.

[6] Lee, S.H., Tanaka, T., Nonaka, G., \& Nishioka, I. (1990). Tannins and related-compounds 95. isolation and characterization of helioscopinins and helioscopins, 4 new hydrolyzable tannins from Euphorbia helioscopia L. Chemical and Pharmaceutical Bulletin, 38, 15181523.

[7] Park, K.H., Koh, D., Lee, S., Jung, I., Kim, K.H., Lee, C.H., Kim, K.H., \& Lim, Y. (2001). Anti-allergic and anti-asthmatic activity of helioscopinin-A, a polyphenol compound, isolated from Euphorbia helioscopia. Journal of Microbiology and Biotechnology, 11, 138142.

[8] Cummings, J.L. (2004). Alzheimer's disease. The New England Journal of Medicine, 351, $56-67$.

[9] Tu, Y., Huang, J., \& Li, Y. (2017). Anticholinesterase, antioxidant, and beta-amyloid aggregation inhibitory constituents from Cremastra appendiculata. Medicinal Chemistry Research, 27, 857-863.

[10] Varadarajan, S., Yatin, S., Aksenova, M., \& Butterfield, D.A. (2000). Alzheimer's amyloid $\beta$-peptide-associated free radical oxidative stress and neurotoxicity. Journal of Structural Biology, 130, 184-208.

[11] Senol, F.S., Orhan, I., Yilmaz, G., Ciçek, M., \& Sener, B. (2010). Acetylcholinesterase, butyrylcholinesterase, and tyrosinase inhibition studies and antioxidant activities of 33 Scutellaria L. taxa from Turkey. Food and Chemical Toxicology, 48, 781-788.

[12] Adams, R.P. (2007). Identification of essential oil components by gas chromatography/quadrupole mass spectrometry. Journal of The American Society for Mass Spectrometry, 16, 1902-1903.

[13] Tel. G., Apaydın. M., Duru. M.E., \& Ozturk, M. (2012). Antioxidant and cholinesterase inhibition activities of three Tricholoma species with total phenolic and flavonoid contents: The edible mushrooms from Anatolia. Food Analytical Methods, 5, 495- 504.

[14] Çayan, F., Tel, G., Duru, M.E., Öztürk, M., Türkoğlu, A., \& Harmandar, M. (2014). Application of GC, GC-MSD, ICP-MS and spectrophotometric methods for the determination of chemical composition and in vitro bioactivities of Chroogomphus rutilus: The edible mushroom species. Food Analytical Methods, 7, 449-458.

[15] Slinkard, K., Singleton, V.L. (1977) Total phenol analyses: Automation and comparison with manual methods, American Journal of Enology and Viticulture, 28, 49-55.

[16] Park, Y.K., Koo, M.H., Ikegaki, M., \& Contado, J.L. (1997). Comparison of the flavonoid aglycone contents of Apis mellifera propolis from various regions of Brazil. Brazilian Archives of Biology and Technology, 40, 97-106. 
[17] Ellman, G.L., Courtney, K.D., Andres, V., \& Featherston, R.M. (1961). A new and rapid colorimetric determination of acetylcholinesterase activity. Biochemical Pharmacology, 7, 88-95.

[18] Weatherburn, M.W. (1967). Phenol-hypochlorite reaction for determination of ammonia. Analytical Chemistry, 3, 971-974.

[19] Fokialakis, N., Melliou, E., Magiatis, P., Harvala, C., \& Mitaku, S. (2003). Composition of the steam volatiles of six Euphorbia spp. from Greece. Flavour and Fragrance Journal. $18,39-42$.

[20] Mateo, C., Calderón, J., \& Sanz, J. (1988). Essential oils of some Sideritis species from central and southern Spain. Phytochemistry, 27, 151-153.

[21] Bravo, L. (1988). Polyphenols: Chemistry, dietary sources, metabolismand nutritional significance. Nutrition Reviews. 56, 317-333.

[22] Sen, S., De, B., Devanna, N., \& Chakraborty, R. (2013). Total phenolic, total flavonoid content, and antioxidant capacity of the leaves of Meyna spinosa Roxb., an Indian medicinal plant. Chinese Journal of Natural Medicines, 11(2), 0149-0157.

[23] Maoulainine, L.B.M., Jelassi, A., Hassen, I., \& Boukhari, O.M.S.O.A. (2012). Antioxidant proprieties of methanolic and ethanolic extracts of Euphorbia helioscopia (L.) aerial parts. International Food Research Journal, 19(3), 1125-1130.

[24] Zhang, D., Zheng, X.Y., Yan, X.W., Cao, W.G., \& Wang, G. (2011). Determination of total flavonoids and rutin in Euphorbia helioscopia L. from Chongqing. Medicinal Plant, 2(7), 30-32.

[25] Rauf, A., Qaisar, M., Uddin, G., Akhtar, S., \& Muhammed, N. (2012). Antioxidant profile and phytochemical screening of E. helioscopia. Middle-East Journal of Medicinal Plants Research, 1(1), 19-23.

[26] Saleem, U., Ahmad, B., Hussain, K., Ahmad, M., Bukhari, N.I., \& Ishtiaq, S. (2014). Estimation of antioxidant power in various extracts of Euphorbia helioscopia L. with five different in vitro antioxidant models. Asian Journal of Chemistry, 26, 1241-1245.

[27] Vinutha, B., Prashanth, D., Salmab, K., Sreeja, S.L., Pratiti, D., Padmaja, R., Radhika, S., Amit, A., Venkateshwarlu, K., \& Deepak, M. (2007). Screening of selected Indian medicinal plants for acetylcholinesterase inhibitory activity. Journal of Ethnopharmacology, 109, 359-363.

[28] Pisano, B., Cosentino, S., Viale, S., Spanò, D., Corona, A., Esposito, F., Tramontano, E., Montoro, P., Tuberoso, C.I.G., Medda, R., \& Pintus, F. (2016). Biological activities of aerial parts extracts of Euphorbia characias. BioMed Research International, 2016. 11 pages.

[29] Zengin, G., Uysal, A., Aktumsek, A., Mocan, A., Mollica, A., Locatelli, M., Custodio, L., Neng, N.R., Nogueira, J.M.F., Aumeeruddy-Elalfi, Z., \& Mahomoodally, M.F. (2017). Euphorbia denticulata Lam.: A promising source of phyto-pharmaceuticals for the development of novel functional formulations. Biomedicine \& Pharmacotherapy, 87, $27-$ 36.

[30] Gholamhoseinian, A., Moradali, M.N., \& Sharifi-far F. (2009). Screening the methanol extracts of some Iranian plants for acetylcholinesterase inhibitory activity. Research in Pharmaceutical Sciences, 4(2), 105-112.

[31] Ahmad, V.U., Hussain, J., Hussain, H., Jassbi, A.R., Ullah, F., Lodhi, M.A., Yasin, A., \& Choudhary, M.I. (2003). First natural urease inhibitor from Euphorbia decipiens. Chemical and Pharmaceutical Bulletin, 51, 719-723. 
[32] Ahmad, V.U., Hussain, J., Hussain, H., Farooq, U., Ullah, F., Lodhi, M.A., \& Choudhary, M.I. (2005). Two new diterpene polyesters from Euphorbia decipiens. Natural Product Research, 19, 267-274.

[33] Lodhi, M.A., Hussain, J., Abbasi, M.A., Jassbi, R., Choudhary, M.I., \& Ahmad, V.U. (2006). A new Bacillus pasteurii urease inhibitor from Euphorbia decipiens. Journal of Enzyme Inhibition and Medicinal Chemistry, 21(5), 531-535.

[34] Minozzo, B.R., Leme, B.M., Justo, A.D.S., Lara, J.E., Petry, V.E.K., Fernandes, D., Belló, C., Vellosa, J.C.R., Campagnoli, E.B., Nunes, O.C., Kitagawa, R.R., Avula, B., Khan, I.A., \& Beltrame, F.L. (2016). Anti-ulcer mechanisms of polyphenols extract of Euphorbia umbellata (Pax)Bruyns (Euphorbiaceae). Journal of Ethnopharmacology, 191, 29-40. 